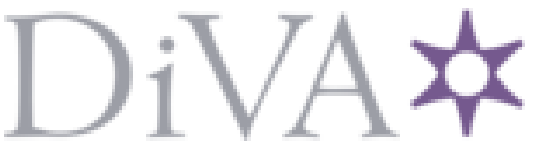

http://www.diva-portal.org

Postprint

This is the accepted version of a chapter published in The Palgrave Encyclopedia of the Possible.

Citation for the original published chapter:

Luis, d M. (2021)

Crealectic Intelligence

In: Vlad Petre Glăveanu (ed.), The Palgrave Encyclopedia of the Possible Cham, UK:

Palgrave Macmillan

https://doi.org/10.1007/978-3-319-98390-5_186-1

N.B. When citing this work, cite the original published chapter.

Permanent link to this version:

http://urn.kb.se/resolve?urn=urn:nbn:se:uu:diva-446450 
(C) The Author(s), under exclusive licence to Springer Nature Switzerland AG 2021

The Palgrave Encyclopedia of the Possible

10.1007/978-3-319-98390-5_186-1

\title{
Crealectic Intelligence
}

Luis de Miranda ${ }^{1}$

(1)Uppsala University, Uppsala, Sweden

\section{Luis de Miranda}

Email: luis.demiranda@idehist.uu.se

\begin{abstract}
The emerging crealectic frame posits that there are three complementary and effectual domains of intelligence, namely analytic, dialectic, and crealectic, being alternatively or complementarily used in human interactions with the world. The focus of crealectic intelligence is the relative possibilization and local realization of absolute possibility, the becoming real, biological, and social of creation. This multimodal externalization and asymptotic unification of a cosmological flux expresses itself via three realms of possibilization: physical (corresponding to analytic intelligence), psychological (corresponding to dialectic intelligence), and philosophical (corresponding to crealectic intelligence). But the philosophical possible is not merely abstract; it originates a generative process of exteriorizations, interiorizations, dissolutions, and unifications transforming the possible into realities. The term "crealectics," coined by philosopher and author Luis de Miranda ( Paridaiza. Plon, Paris, 2008), is a compound of "Creal" (from "creative" and "Real") and of two possible suffixes: "logos" (from the Greek word designating a universalized meaning) or "ektos" (from the Greek root meaning "toward the outside," "outer," or "external"). The ontological core of crealectics, the Creal, is the immanent process of creation understood as a ubiquitous stream of absolute possibility exteriorizing itself. For a crealectician, philosophy is not the mere logical analysis of truth conditions, but
\end{abstract}


the self-questioning enterprise of thought regarding its own possibilizing and world-making power.

Keywords Crealectics - Dialectics - Intelligence - Creal - Possible - Creation - Process philosophy

\section{Introduction: Multifarious Intelligence}

The crealectic frame posits that there are at least three complementary modes of intelligence, namely analytic (an objectifying discretization of the real in which machines may excel), dialectic (which deals with meaningful and often bipolar contrasts between entities or positions), and crealectic (which deals with potentials, actualizations, and unifications of absolute multiplicity). No healthy society may be possible without a holistic harmonization of these three performative aspects of thinking.

While the idea that there are several kinds of human intelligence (see "Intelligence") became mainstream by the end of the twentieth century (Sternberg and Kaufman 2011), there is no general agreement on what these different kinds might be. The very etymology of the word intelligence is ambivalent, between the two roots inter-legere and inter-ligare. Intelligence can be about inter-legere, to read between the lines, to distinguish, and to discriminate - "the world is an immense chaos of interactions, but in this immense chaos of interactions comes a human being who will know how to choose from this multiplicity" (Jousse 2016, p. 29). Yet, the root of intelligence can also be inter-ligare, to create links and connections: "Discoveries consist of bringing together ideas $[\ldots]$ that are susceptible to join but that had not been hitherto been joined" (ibid.). Whether intelligence consists in picking and distinguishing parts by a process of division and segmentation, for instance, via the analytic method in science; or in discovering wholes, syntheses, and unities by a process of association, for example, in dialectic thinking; or, third, and more actively, in generating actualizations of hidden potentialities (see "Potential") - not to speak of the various historical, cultural, and disciplinary variations in defining intelligence around the globe - its polysemy of practices confirms the necessity of abandoning the view that intelligence is a universal form of manipulating symbols, one that could eventually be fully systematized in a 
series of protocols or algorithms. The Crealectic approach is particularly interested in the aspect of intelligence that deals with the philosophical possible and its actualizations.

The slow but steady development of the domain of "artificial intelligence" (AI) since the coining of the term in 1956 by John McCarthy et al. (O'Regan 2012) has not only added a new layer of complication to the understanding of what minds can do (Jacob 1997), but it has also in contradistinction induced the question of what "natural intelligence" might be (de Callataÿ 1992; Estep 2006). By natural here, we mean what a living human intelligence can access without the help of computers, leaving open for further debate the question of animal, plant, or alien intelligences. In order to define natural intelligence, one needs to provide a definition of what nature is, at least axiomatically. This is what the notion of "crealectic intelligence" does, by equating the essence of Nature with the processphilosophical concepts of "Creal," "Creative Real" (de Miranda 2017, 2020a), "foundational process of creativity" (Whitehead 1929, p. 160), or "creative evolution" (Bergson 1911).

\section{Definition and History}

Crealectic intelligence is natural intelligence inasmuch as the essence of Nature - and therefore of Culture - is defined as a creative process of externalizations, interiorizations, dissolutions, and unifications grounded in absolute possibility. The term "crealectics," originally coined by philosopher and author Luis de Miranda ( 2017), is a compound of "Creal" (from "creative" and "Real") and of two possible suffixes: "logos" (from the Greek word designating a unifying meaning) and "ektos" (from the Greek root meaning "toward the outside," "outer," or "external"). The word Creal (French Créel) itself was coined by de Miranda in his French science-fiction novel Paridaiza ( $\underline{2008}$, English translation 2020), in which the characters are immersed in a totalitarian duplication of the Earth created through virtual reality and AI technologies (see "Virtual Reality"), an addictive simulation (see "Virtual Worlds") that maintains humanity in a state of sensual dependence and immaturity.

A group of rebels manages, however, to create a liberating virus that shall free the alienated users of Paridaiza, via a coded signifier which they initially call Strait. Magellan ${ }^{\text {, }}$, the first insurgent avatar who benefits from the Strait treatment, has the vision of "a world he has spontaneously named the Creal." (2020, p. 151). As per the published English translation of the novel $(\underline{2020 b})$ : 
"You're going to think I'm on drugs. The first impression I had was of being in a different universe from Paridaiza, maybe even an opposite one. There was a kind of explosion, and I found myself in the corner of a sort of cloister, with a garden and a fountain."

"Did it look like a place you'd seen before?" asks Clara ${ }^{\mathrm{x}}$.

"Nothing was familiar, not even the smells, but at the same time I felt at home. I felt like I was inside a living kaleidoscope that would obey my commands. And it was as if there was honey flowing in my veins, an intense flow of desire. The path leading to the fountain formed a kind of maze that shifted and changed with every step I took. Shining, brightly-colored shapes were transforming constantly. I looked up and realized that the cloister didn't have any walls, only peristyle columns. How can I describe it? I felt like this world was my own creation in a way, but at the same time I was only the instrument of a divine harmony." [...]

"But why Creal? Why did that neologism come to you so suddenly out of nowhere?"

"I don't know. I felt like I was entering the very depths of imagination and the heart of reality at the same time."

"And you felt good?"

He concentrates, searching for the right words.

"Yes, it was truly a feeling of joy and confidence. I felt powerful, too, but with a gentle, harmonious kind of power."

"Was that the effect of a series of coincidences? Of synchronicity?"

"It was like I'd touched the very essence of my own being. I felt like everything was connected."

Gagarina ${ }^{x}$ 's face lights up.

"This magical cloister with a fountain in the center... that exactly matches the description of what people called Paridaiza in the time of the prophet Zoroaster. The true Paridaiza, the one represented on my Persian rug, and not a gilded prison filled with greedy avatars. That is your Creal: the secret of the original Paridaiza."

"What secret?"

"None other than our spiritual roots. The yearning creativity that is the very essence of life. The imaginative desire that triumphs over our sinking, our collapse. The ancients called it the Poem of the Cosmos." 
"You seem to know a lot about it. What does any of this have to do with the code word Strait?"

"The Creal is the strait." (pp. 151-154)

From the context of the fictional birth of the signifier, the reader may observe that Creal is defined as the "yearning creativity that is the very essence of life" and that, as a human essential possibility, it points to a harmonious unification of the subjective and objective experiences of the world.

The idea that creation or creativity is an immanent rather than only transcendent cosmological principle is typical of process philosophies, both Western and Eastern, for example, in Heraclitus (Holm-Hadulla 2013, p. 297), Taoism (Yu 1981), Bergson (see "Bergson"), or Alfred North Whitehead (see "Alfred North Whitehead") for whom "Creativity is the universal of universals characterizing ultimate matter of fact." ( $1929, \mathrm{p}$. 31). This onto-generative notion of creative becoming (Cheng 2018) has also been equated with a becoming-world of sublimity or absolute possibility (de Miranda 2020a). The object of crealectic intelligence is thus the relative possibilization and realization of possibility, the constant becoming real, biological, and social of natural creation, and the multimodal externalization and adunation of the multiple as source. While the generative concept of Creal is an all-encompassing ontological a priori, crealectic intelligence is an art or process of actualization more or less present in any singular transformation of the world. The more a protocol is repeated automatically, the more its crealectic capacity to actualize the possible is reduced. This is why a world ruled by computers, algorithmic standards, pervasive norms, bureaucracy, and other forms of "anthrobotics" is a danger to our relationship with absolute possibility (de Miranda, Ramamoorthy and Rovatsos 2016).

\section{Crealectic Intelligence Versus Analytic Intelligence and Dialectic Intelligence}

The experience of awe (see "Awe"), wonder (see "Wonder"), admiration, or imaginative questioning, which Aristotle and Descartes considered to be attuned to the origin of philosophy, may be seen as superfluous in sociotechnical protocols which are attached to an analytic exhaustion or exploitation of the Real. Mundane practices of engineering or mathematical ordering tend to keep the imaginative or desiring subject out of their equations in order to achieve an operational description and management of a system or problem. The 
early inventors of computational thinking were already aware that an essential part of intelligence was left behind in their analytic endeavors, namely a relationship to creativity and truth. When Charles Babbage and Ada Lovelace designed the first "Analytical Engine" by associating analysis with a mechanical function of "operation" (Menabrea 1961, p. 247), Lovelace was careful to add: "The Analytical Engine has no pretensions whatever to originate anything. It can do whatever we know how to order it to perform. It can follow analysis; but it has no power of anticipating [...(see anticipation)...] relations or truths." (p. 284). Analytics cannot by itself provide meaning, nor creative unification.

Analytic forms of intelligence were, however, a significant step in human evolution. Some 18 centuries ago, in his account of Aristotle's Analytics, Alexander of Aphrodisias wrote that the one who "uses analysis [...] reduces composite bodies into simple bodies" (c.200 $\mathrm{CE}, 49, \S 2.4$ ), thus separating an unknown into parts that are known (Arnauld and Nicole $\underline{1996}$, p. 200). Analytic elements manifest as what Noam Chomsky called a "surface structure" ( $\underline{1968}$, p. 30), represented by discrete symbols such as letters, code, labels, or forms; analytic intelligence thus considers reality as a readable corpus or text. It is a moment of distinctive literacy facilitating communication and the effectual manipulation of the Real. The analytic moment is the consideration of the world as possible syntax instead of chaos, or, in the language of artificial intelligence, patterns versus noise.

Searle's famous distinction between syntax and semantics ( $\underline{1980}$ ) aimed at explaining why computers do not have an understanding of what they do and therefore cannot be said to be intelligent: "Computation is defined purely formally or syntactically, whereas minds have actual mental or semantic contents, and we cannot get from the syntactical to the semantic just by having the syntactical operations and nothing else" (Searle 2010, p. 17). Beyond these traditional objections to artificial intelligence, there is what we might call the Whiteheadian objection to the belief that analysis and its concreteness are sufficient to understand the Real: analytic intelligence, while useful for purposes of manipulation and operationality, often ends up mistaking the abstract object for the concrete in a "fallacy of misplaced concreteness" (Whitehead 1926, p. 64). Out of habit or cognitive bias, we tend to believe that the parts, units, or functions that we distinguish and name are truly there in the real world, like cogs in a machine rather than metaphors. If we take the example of mental health diagnoses, such as bipolarity, depression, or attention deficit hyperactivity disorder, the fallacy of misplaced concreteness pushes individuals to consider these diagnoses as describing their essential identity or inner nature. Seeing their soul as a psychiatric object 
rather than a site of self-possibility, these individuals are led to believe that other objects such as pills, via the mechanical law of causality, can regulate their being in the world.

Yet, phenomena of reality ambivalence (see "Tolerance of Ambiguity") happen precisely because our cognition is not only analytic but also cocreative (Berthoz 2012). Our consciousness produces semblances of emergence (see "Emergence") and meaning that supersede the sum of the observed parts and cannot be explained by strict analysis (Murphy and Stoeger 2007). In the past, analytic philosophers, tempted by materialism and the ideology of concreteness, have ironically called this surplus of meaning the "ghost in the machine" (Ryle 2009 [1949], p. 5). According to the crealectic frame, to call what we experience but cannot fully analyze, measure, demonstrate, or materially evidence a "ghost," or speculative superstition, partakes in a reductionism that can be "detrimental both to good science and good human living" (Thompson 1997, p. 219). Ultimately, it is claimed that crealectic intelligence is already present in protocols that are usually seen as purely analytic, for example, the selection or distinction between useful data and neglectable noise.

Social intelligence implies a discursive negotiation and a creative focus that requires the concurrent display of dialectics (see "Dialectics") and crealectics. Since Plato, dialectic intelligence designates an interpretative conversation in which there is a more or less rational tension between different or agonistic perspectives (from dialegesthai: to talk through). Dialectics is "the progression of thought through the appearance of oppositions within one and the same unity" (Bloch 1983, p. 288). This form of thinking can be performed between different subjects or within the same personal mind, as in Socrates's inner dialogue with his guardian divinity, his daimonion (McMahon 2013, p. 40), or as in Descartes' cogito, which can be defined as the human capacity for internalized individual dialectics, a form of consciousness that is capable of self-contradiction or self-examination.

In Hegel's variant, dialectic intelligence describes the ubiquitous and necessary unfolding of a time-dependent process of negations and performative contradictions toward the realization of absolute Spirit. Hegelians believe that the Real is itself dialectical, and therefore that dialectic intelligence is a privileged form of deterministic realism leading to objective knowledge: "the dialectical constitutes the moving soul of scientific progression" (Hegel 1817, §81). In Hegelian dialectic consciousness, a proposition and its opposite can be both true, thus apparently ignoring the law of noncontradiction common in analytic logic. For instance, daydreaming and working: Every artisan or creator knows that daydreaming is not the opposite of working, but a modality of making-possible. Individual, bilateral, or 
collective forms of dialectic intelligence rely on polarities, tensions, and potential contradictions in a process that is ideally moving toward a form of reconciliation, resolution, or synthesis that reflects the movement of the "World-Soul" toward the realization of freedom on earth (Hegel 1806, p. 114).

The crealectic view argues, however, that when fetishized as a one-size-fits-all tool, as for example in the Marxist variant, or the Sophists' version of the Ancient Greek variant, dialectics sometimes forces unnatural syntheses. In the agonistic world of dialectics, the illusion might be that there is not enough space for all, and it becomes difficult to identify if a synthesis is logical or rather belongs to a power struggle between different interests. Few can avoid being emotional in an antagonistic dialogue, and even Hegel admitted the importance of passion in dialectic unfolding. Hypercommunitarian times demonstrate the pitfalls of dialectics: Any legitimate position of dominance can be seen as a scandalous usurpation. Incessant phenomena of polarization of worldviews, accelerated by digital echo chambers, manifest a possible enclosure of dialectics into a friend-enemy or same-different combat.

The dialectic stage of understanding is necessary to transform a reading of signs into a deliberative interpretation that subsumes real or apparent contradictions. However, this moment of intelligence is not sufficient to act upon the world because the synthesis it proposes can be contested and, by definition, negated anew: If the world is only dialectically interpreted, it may become an interminable process in which everything turns negative and positive alternatively, any synthesis being an ephemerous plateau collapsing into a new thesis-antithesis dynamic. Dialectics tends to fall into binary dichotomies, which are themselves cognitive reductions, even if the intention is to introduce more complexity than analytic intelligence (Elbow 1993). For example, the two categories of disease and normal health are oblivious of possible alternative mental or physical states that are neither normal nor unhealthy (Canguilhem 1991, p. 97). The human phenomenon of psychological resilience is neither pathological nor normal: It is a "novelty," a manifestation of crealectic intelligence (de Miranda 2019).

Social reality is polysemantic and implies a multiplicity of decisions and acts in which the very factualization of data, the attribution of a syntax to a given reality, are already filtered by creative and active imagination (see "Imagination") and an embodied perspective. Crealectics aims at describing the form of consciousness that is aware of acting as an 
engaged and unified person upon a world of multiplicity with the ideal of cocreation in mind.

Crealectic intelligence transcends the borders of the actual and of the Real and, therefore, is related to the experience of sublimity. Artists have known or felt for long enough that creativity as ultimate principle is a relationship with the intuitions of alterity, of wholeness, and of the sublime, "the incommensurability of reality to concept" (Lyotard 1984, p. 79). Even for nonartistic practitioners, the experience of the sublime, for instance, in contemplating nature or in confronting a new culture, manifests itself as surreal or hyperreal awe, beyond the analytic routines: "Sublimity lifts the Absolute above every immediate existent and therefore brings about the liberation which, though abstract at first, is at least the foundation of the spirit" (Hegel 1835, p. 362).

Sublime feeling sensitizes us to an "outside and an inside" in thought, to a creative "hyperdialectic" between imagination, reason, flesh, plurality, and ambiguity (Merleau-Ponty 1968 , p. 94). Within the crealectic approach, healthy human life and healthy thought need to host regular moments of felt sublimity, as a necessary condition to reconnect with the possibility of regeneration or novelty. The intuition of creal sublimity, the possible as absolute, becomes "the transport that leads all thought (critical thought included) to its limits" (Lyotard 1994, x). This paradoxical capacity to pursue belief or knowledge about something we typically ignore, but feel or desire to be real, can be productive of new knowledge and new forms of dealing with existence: It suggests the effectual agency of what Einstein called "creative imagination" (Holton 1978, p. 96). Notoriously, Einstein was often daydreaming about the possible in order to actualize new forms of understanding nature, space, and time.

\section{Crealectics and the Possible}

In remaining open to the "creative generosity" of life (Canguilhem 1991, p. 188), the democratization of crealectic intelligence may allow for a new form of global consciousness, one that would expand the domains, diversity, and agency of the possible (see "Possible in Philosophy"). Crealectics is a program of harmonization of our capacity to feel, imagine, envision, realize, and actualize a world emerging from the cosmological source of the Real as a metaphysical "possibility of possibility" (Slife 1994). Crealectic 
intelligence deals with processing realities and imaginaries of novelty and plurality rather than mere contradiction of binary polarities or analytic operation of known bits; its ontological core is the philosophical idea of creation understood ontologically as a ubiquitous stream of absolute possibility (Bergson 1911; Whitehead 1929; Deleuze and Guattari 1994; de Miranda 2017). We may think of the crealectic emotion as the opposite of depression. In the latter experience, one may feel like the earth is an empty rock, devoid of anything but cardboard illusions. In the crealectic experience of the world, we are not looking at reality as a source but as a compossible manifestation and interpretation among many others of creality, a source of infinite abundance of possibility.

As was understood by existentialist philosophers, chief among them Sartre and Heidegger, the universe is a possibilization furnace. The simultaneously immanent and transcendent "transimmanent" (Nancy $\underline{1996}$, p. 48) - ground of ever-emerging possibilization ( Ermöglichung) is conceived as opening for the making-possible (Heidegger 1995, p. 364; 1996, p. 244). This cosmological opening may be summarized in a simple modal formula: "It is possible," where It designates the ultimate being-becoming (de Miranda 2020a). “There is a practical consciousness, an 'I can' that underlies and precedes the reflective selfconsciousness of the 'I think', but the 'I can' is given and coeval with an 'it can"' (Sinclair $\underline{2017}$, p. 191). The Surrealists, for instance, trusted this source of creation when they produced their works of art based on letting go of the obsession of controlling consciousness analytically.

When one embodied living being says and feels, of a projected situation or idea, for instance, that it is possible, they are connecting with the modal creal spacetime. The embodied formula is - at least asymptotically - performative: It begins to produce something, it is the gateway to transform a virtuality into a reality, and it possibilizes or " crealectizes" (de Miranda 2020a). The felt experience of possibility creates a bridge between the imaginary and the real. Human instances of this generative feeling abound: Think of any founder slowly manifesting, day after day, the metamorphosis and growth of an impression or ideal into a real space of experience.

In other words, as argued by Bergson, the possible is not a deterministic program contained in the past, but rather continuous participative co-creation, or "organic possibility" (Gunter 2007, p. 38): “This extensive continuum expresses the solidarity of all possible standpoints throughout the whole process of the world" (Whitehead 1929, p. 103). In order to express the interdependence not only of all things but also of the physical, the 
psychological, and the spiritual realms, the crealectic approach distinguishes threes modes of possibility which correspond to the three types of intelligence we have evidenced: the physical possible, the psychological possible, and the philosophical possible. The physical possible relates to conditions toward the analytic realization of discretizable things via material causality. The psychological possible relates to the dialectic realm and its movements of tensions, dualities, and degrees of liberty or alterity. The third mode, the philosophical possible, originates in the crealectic intelligence process, by which thought as a spiritual property of the universe transmutes (into) the other two possibles. Attempts at explaining how this transmutation might be brought about constitute the history of philosophy itself, from Plato to Hegel et al., from hermeticism to process philosophy. For a crealectician, philosophy is not the mere logical analysis of truth conditions, but the selfquestioning enterprise of thought regarding its own possibilizing and world-making power. Thought, desire, persistence are performative; crealectic intelligence is generative.

\section{Summary}

The term "crealectics," coined by philosopher and author Luis de Miranda ( 2017), is a compound of "Creal" (from "creative" and "Real") and of two possible suffixes: "logos" (from the Greek word designating a universalized meaning) or "ektos" (from the Greek root meaning "toward the outside," "outer," or "external"). Crealectics addresses the intuitive way through which we unify realities and imaginaries of novelty, plurality, and ambiguity, in a cocreative manner rather than via mere contradiction of binary polarities or analytic operation of known bits. The ontological core of crealectics, the Creal, is the idea of creation understood ontologically as a ubiquitous and transimmanent stream of absolute possibility. The crealectic frame posits that there are three complementary and effectual domains of intelligence, namely analytic, dialectic, and crealectic, being alternatively or complementarily used in human interaction with the world. The objects of crealectic intelligence are the relative possibilization and realization of absolute possibility, the becoming real, biological, and social of creation, and the multimodal externalization and asymptotic unification of an axiomatic creative flux, via three realms of possibilization, physical, psychological, and philosophical. 
Cross-References

- Anticipation

- Awe

- Bergson

- Dialectics

- Emergence

- Imagination

- Intelligence

- Possible in Philosophy

. Potential

- Tolerance of Ambiguity

. Virtual Reality

. Virtual Worlds

. Wonder

\section{References}

Arnauld, A., \& Nicole, P. (1996). Logic or the art of thinking (J. V. Buroker, Trans.). Cambridge: Cambridge University Press.

Bergson, H. (1911). Creative evolution. New York: Holt.

CrossRef

Berthoz, A. (2012). Simplexity: Simplifying principles for a complex world. New Haven: Yale University Press.

CrossRef 
Bloch, E. (1983). The dialectical method (J. Lamb, Trans.). Man and World, 16(4), 281313.

CrossRef

Canguilhem, G. (1991). The normal and the pathological (C. R. Fawcett, Trans.). New York: Zone Books.

Cheng, C. Y. (2018). On the ultimate as the onto-generative origin in the Hengxian. Journal of Chinese Philosophy, 45(3-4), 133-135. https://doi.org.ezproxy.its.uu.se/10.1111/ $1540-6253.12376$.

Chomsky, N. (1968). Language and mind. New York: Harcourt Brace Jovanovich.

De Callataÿ, M. (1992). Natural and artificial intelligence. Amsterdam: Elsevier North Holland.

De Miranda, L. (2008). Paridaiza. Paris: Plon.

De Miranda L, Ramamoorthy R, Rovatsos M (2016). We, anthrobot: Learning from human forms of interaction and esprit de corps to develop more diverse social robotics. In What Social Robots Can and Should do (pp. 48-56). Amsterdam: IOS Press.

De Miranda, L. (2017). On the concept of creal: The politico-ethical horizon of a creative absolute. In P. de Assis \& P. Giudici (Eds.), The dark precursor: Deleuze and artistic research (Vol. II). Leuven: Leuven University Press. 
De Miranda, L. (2019). Being and neonness. Cambridge: MIT Press.

CrossRef

De Miranda, L. (2020a). Artificial intelligence and philosophical creativity: From analytics to crealectics. Human Affairs, 30, 597-607.

CrossRef

De Miranda, L. (2020b). Paridaiza (T. Kover, Trans.). Sacramento: Snuggly Books.

Deleuze, G., \& Guattari, F. (1994). What is philosophy? (H. Tomlinson \& G. Burchell, Trans.). New York: Columbia University Press.

Elbow, P. (1993). The uses of binary thinking. Journal of Advanced Composition, 13(1), $51-78$.

Estep, M. (2006). Self-organising natural intelligence: Issues of knowing, meaning and complexity. Dordrecht: Springer.

Gunter, P. A. Y. (2007). Bergson's creation of the possible. Substance, 36(3), 114, 33-41. CrossRef

Hegel, G. W. F. (1806/1984). Letter to Friedrich Niethammer, 13 October 1806. In C. Butler \& C. Seiler (Trans.), The letters. Bloomington: Indiana University Press.

Hegel, G. W. F. (1817/1991). The encyclopaedia logic (T. F. Geraets, W. A. Suchting, \& H. S. Harris, Trans.). Indianapolis: Hackett. 
Hegel, G. W. F. (1835/1975). Aesthetics: Lectures on fine art (Vol. 1, p. 362) (T. M. Knox, Trans.). Oxford: Oxford University Press.

Heidegger, M. (1995). The fundamental concepts of metaphysics (W. McNeill \& $\mathrm{N}$. Walker, Trans.). Bloomington/Indianapolis: Indiana University Press.

Heidegger, M. (1996). Being and time (J. Stambaugh, Trans.). Albany: SUNY Press.

Holm-Hadulla, R. M. (2013). The dialectic of creativity: A synthesis of neurobiological, psychological, cultural and practical aspects of the creative process. Creativity Research Journal, 25(3), 293-299. https://doi.org/10.1080/10400419.2013.813792.

CrossRef

Holton, G. (1978). The scientific imagination: Case studies. Cambridge: Cambridge University Press.

Jacob, P. (1997). What minds can do: Intentionality in a non-intentional world. Cambridge: Cambridge University Press.

CrossRef

Jousse, M. (2016). In search of coherence (E. Sienaert, Trans.). Eugene: Pickwick Publications.

Lyotard, J.-F. (1984). The postmodern condition: A report on knowledge (G. Bennington \& B. Massumi, Trans.). Minneapolis: University of Minnesota Press. 
Lyotard, J.-F. (1994). Lessons on the analytic of the sublime (E. Rottenberg, Trans.). Stanford: Stanford University Press.

McMahon, D. M. (2013). Divine fury: A history of genius. New York: Basic Books.

Merleau-Ponty, M. (1968). The visible and the invisible. (A. Lingis, Trans.). Evanston: Northwestern University Press.

Menabrea, L. F. (1961). Sketch of the analytical engine invented by Charles Babbage. In P. Morrison \& E. Morrison (Eds.), Charles Babbage and his calculating engines; selected writings by Charles Babbage and others (pp. 225-297). New York: Dover.

Murphy, N., \& Stoeger, W. R. (2007). Evolution and emergence: Systems, organisms, persons. Oxford: Oxford University Press.

Nancy, J.-L. (1996). The muses (P. Kamuf, Trans.). Stanford: Stanford University Press.

O'Regan, G. (2012). Artificial intelligence. In A brief history of computing. London: Springer. https://doi-org.ezproxy.its.uu.se/10.1007/978-1-4471-2359-0_15.

CrossRef

Ryle, G. (2009). The concept of mind. London/New York: Routledge.

CrossRef 
Searle, J. (1980). Minds, brains and programs. Behavioral and Brain Sciences, 3(3), 417457.

CrossRef

Searle, J. (2010). Why dualism (and materialism) fail to account for consciousness. In R. E. Lee (Ed.), Questioning nineteenth century assumptions about knowledge. New York: Suny Press.

Sinclair, M. (2017). The actual and the possible: Modality and metaphysics in modern philosophy. Oxford: Oxford University Press.

CrossRef

Slife, B. D. (1994). The possibility of possibility. Journal of Theoretical and Philosophical Psychology, 14(1), 96-101.

CrossRef

Sternberg, J. T., \& Kaufman, S. B. (Eds.). (2011). The Cambridge handbook of intelligence. Cambridge: Cambridge University Press.

Thompson, H. E. (1997). The fallacy of misplaced concreteness: Its importance for critical and creative inquiry. Interchange, $28(2 \& 3), 219-230$.

CrossRef

Whitehead, A. N. (1926). Science and the modern world. Cambridge: Cambridge University Press.

Whitehead, A. N. (1929). Process and reality. New York: Macmillan. 
Yu, D. C. (1981). The creation myth and its symbolism in classical Taoism. Philosophy East and West, 31(4), 479-500. https://doi-org.ezproxy.its.uu.se/10.2307/1398794.

CrossRef 